\title{
Distribution and Impact of Invasive Parthenium hysterophorus on Soil Around Arusha National Park, Tanzania
}

\author{
Fredrick Ojija ${ }^{1, *}$, Ndaki Marco Manyanza ${ }^{2}$ \\ ${ }^{1}$ Department of Applied Sciences, College of Science and Technical Education, Mbeya University of Science and Technology, Mbeya, \\ Tanzania \\ ${ }^{2}$ Department of Natural Sciences, College of Science and Technical Education, Mbeya University of Science and Technology, Mbeya, \\ Tanzania
}

Email address:

fojija@mustnet.ac.tz (F. Ojija)

*Corresponding author

\section{To cite this article:}

Fredrick Ojija, Ndaki Marco Manyanza. Distribution and Impact of Invasive Parthenium hysterophorus on Soil Around Arusha National Park, Tanzania. Ecology and Evolutionary Biology. Vol. 6, No. 1, 2021, pp. 8-14. doi: 10.11648/j.eeb.20210601.13

Received: December 22, 2020; Accepted: January 6, 2021; Published: February 26, 2021

\begin{abstract}
An increase of biological invasion in developing countries is threatening smallholder's livelihoods, biodiversity conservation, agroecosystems and rangeland productivity. In Tanzania, the exotic invasive plant Parthenium hysterophorus, which is rapidly spreading in Arusha region, threatens wildlife conservation, human well-being and food security in the country. This study was conducted to assess the current distribution of $P$. hysterophorus and its associated soil properties within the Arusha National Park (ANP) and in adjacent villages at the park's border zones using road surveys. Parthenium hysterophorus density was visually estimated as high, medium, and low when the invasive individuals were $>4,3-4$, and $1-2$ in $1 \mathrm{~m}^{2}$ quadrats, respectively. The results showed that albeit some adjacent villages are invaded, ANP is yet not affected. Parthenium hysterophorus was observed growing in grazing areas, maize and banana fields in villages, and along road verges, with particularly high densities in maize fields, along roadsides, and at lower altitudes. Moreover, analysis of soil chemical properties showed that $P$. hysterophorus was associated with soils of higher Manganese and cation exchange capacity. We recommend that P. hysterophorus surveys within the ANP and other protected areas in Arusha region should be carried out regularly as the rapid expansion of $P$. hysterophorus threatens ANP's ecology and biodiversity.
\end{abstract}

Keywords: Africa, Alien Plants, Livelihoods, Soil Properties, Weed Biology, Weed Invasion, Weed Survey

\section{Introduction}

Invasive plants are defined as exotic plant species that when released into novel environments establish, grow, reproduce and sustain self-replacing populations without human intervention $[1,2]$. They exert negative effects on intact and semi-intact ecosystems [3]. Invasive species are characterized by a longer life span and fruiting period, greater seed yield, smaller seed size, easy dispersal by wind, human or animals, stronger vitality, and higher biomass than native species [4]. These characteristics facilitate the spread and invasion of many alien species [5]. Movement of people, transportation of goods, and horticulture contribute considerably to the introduction of exotic invasive species.
Anthropogenic activities resulting in alteration of habitats promote invasion and dispersal of invasive plant seeds [6].

Alien invasion causes potentially harmful impact on native biota conservation [7], ecosystem processes (e.g., nutrient cycling) and services (e.g., pollination, [8]), alters indigenous vegetation structure, ecological communities and fire regime [9]. It reduces the abundance, species richness, and diversity of indigenous plant species [10]. Some alien invasives adversely affect trophic structure, food webs and vertebrates $[11,12]$, as well as invertebrates $[8,13]$. In some cases, alien invasion may even lead to biodiversity loss [1]. Rural communities' livelihoods that depend entirely on natural resources or agriculture are also impacted unfavorably by the invasives [14]. Overall, biological invasion is associated with 
negative impacts on ecology and economy worldwide [3].

An alien invasive plant Parthenium hysterophorus L. (Asteraceae) is known for its deleterious impact on biodiversity, agriculture, and livelihoods of local people (Figure 1, [5, 15]). It is indigenous in Central and South America [16], but has become invasive in Africa, Asia, and Australia [7]. Within its invasive range, P. hysterophorus causes severe harmful effects on the environment [16]. It suppresses natural flora, reduces quantity and quality of palatable fodders as well as crop production [7, 14]. It also interferes with pollination services of native plant species [5], modifies vegetation community structure and exerts harmful health effects to people, livestock and wildlife [4].

Parthenium hysterophorus is a prolific seed producer i.e. producing about $15,000-28,000$ seed on average [4]. Its seeds disperse easily and germinate under wide range of environment condition, i.e., at rainfall of $>500 \mathrm{~mm}$ per year, $10-25^{\circ} \mathrm{C}$ average annual temperatures and a soil $\mathrm{pH}$ of $(2.5-$ 10 [4]. In addition to withstanding saline, drought and moisture stress [4], P. hysterophorus is capable to grow and establish on different soil types i.e. black, clay, alkaline and cracking soils of high fertility [4]. Also, it uses allelopathy to outcompete indigenous plant species [15]. Since in 2010 when P. hysterophorus was first reported in Arusha region, Tanzania it has spread in other four regions i.e. Kagera, Kilimanjaro, Geita and Manyara (Figure 1). It has invaded rangelands and agroecosystems in these regions while reducing crop yield and forage for livestock [5, 15]. As a result, it endangers livelihoods of smallholders and pastoralists.
As it is projected that $P$. hysterophorus will spread further into protected areas in Tanzania [17], it is imperative to understand its current distribution [2]. This information is a vital step for managing and preventing its spread, and developing possible management responses $[2,11]$. Its current spread also indicates when and where management control such as mechanical removal, biological agents, or bioherbicides can be applied, effectively (Figure 3, [1]). Efforts to assess the distribution of invasives has been ongoing in Tanzania but little work has been done to document the distribution of $P$. hysterophorus in and around protected areas. The primary objective of this study was to assess $P$. hysterophorus (i) distribution within and at the border zones of Arusha national park (ANP) and (ii) its association with particular soil chemical properties.

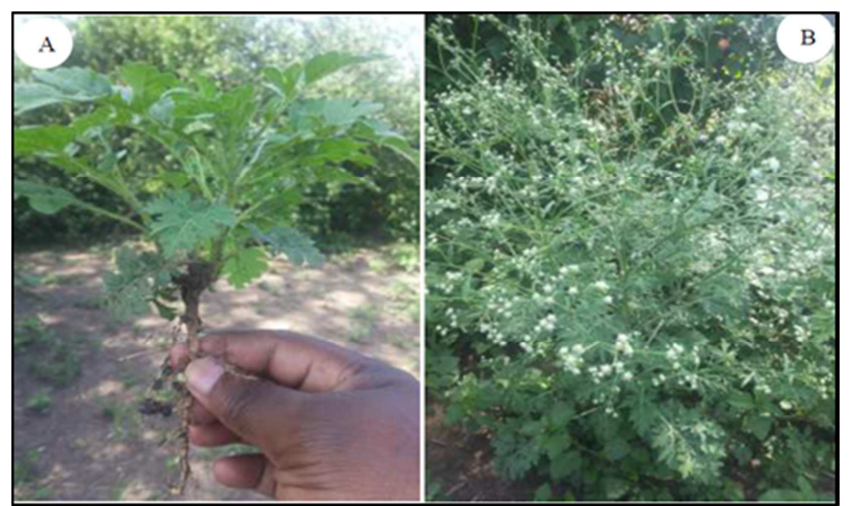

Figure 1. Seedling (A) and mature flowering (B) Parthenium hysterophorus plant in northern Tanzania.

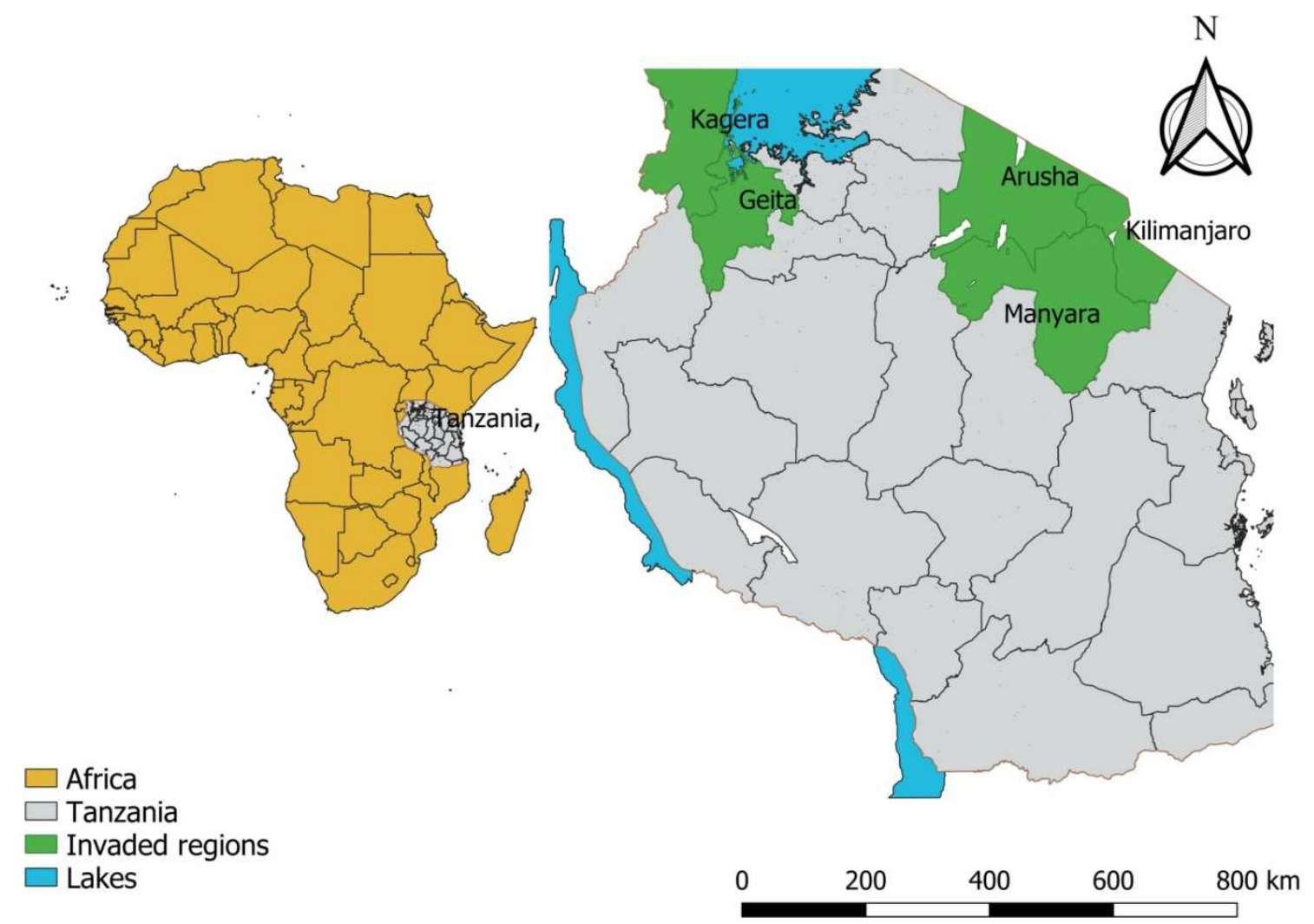

Figure 2. Regions invaded by Parthenium hysterophorus in Tanzania. 


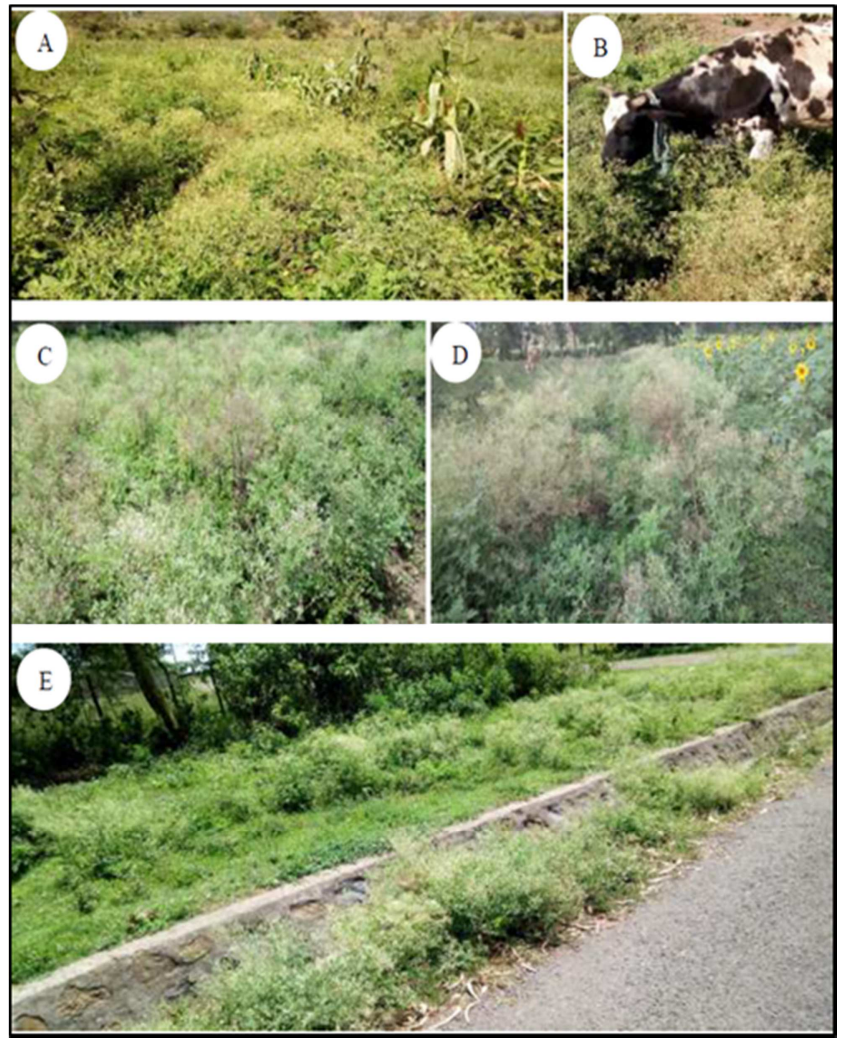

Figure 3. Maize field (A), grazing area (B), rangeland, $(C)$, sunflower field (D), and (E) Momela road heading to Arusha national park (E) invaded by Parthenium hysterophorus in Arusha, Tanzania.

\section{Materials and Methods}

\subsection{Study Sites and Field Survey}

The study was conducted within ANP and villages nearby the park border zones. Arusha national park is located at $3^{\circ} 15^{\prime} \mathrm{S}$ and $37^{\circ} 00^{\prime} \mathrm{E}$ in the Arusha region of Tanzania. The surveys were conducted between January and June, 2018. We used a roadside survey to search for P. hysterophorus along roads, both inside and outside ANP using a vehicle and motorcycle. We stopped after every $30 \mathrm{~m}$ to $50 \mathrm{~m}$ to scan for the presence of $P$. hysterophorus in areas nearby the roads, farms, grazing fields, and settlements and recorded the location of $P$. hysterophorus (Garmin etrex20 GPS). Inside the park, the stops were made at an interval of $1 \mathrm{~km}$ as we expected lower occurrence probability. On every $P$. hysterophorus detection, we recorded latitude, longitude, elevation, land use type, and density per square meter. We estimated visually the density of $P$. hysterophorus as high, medium, and low when P. hysterophorus plants were $>4,3-4$, and 1-2 individuals in $1 \mathrm{~m}^{2}$ quadrat, respectively.

The road survey method was used in this study because we were searching for an invasive species that is known to grow along roadsides (or road verges) and in disturbed areas [18]. The road verge environments are suitable for invasions of alien plants (e.g., P. hysterophorus) because they offer appropriate microhabitat $[19,20]$. The road networks are also known to be a major conduit for dispersal of $P$. hysterophorus seeds at a long distance by vehicles $[20,21]$. Previous studies refer road survey method as a suitable method for assessing and early detection of the population of a single or new known invasive species [18, 22]. The method facilitates rapid assessment of the distribution and diversity of the invasive plant species [21,22].

\subsection{Soil Sampling and Analyses}

During the survey, we randomly selected patches invaded heavily by $P$. hysterophorus and as control patches without invasion (uninvaded) to collect soil samples. The distance between the invaded and uninvaded patches was $30 \mathrm{~m}$. At each selected patch we established $1 \mathrm{~m}^{2}$ plot and removed leaf litter before taking soil samples. Five soil samples (one from the center and one from each of the four corners of the plot to a depth of 10 $\mathrm{cm})$ were collected using a garden trowel. The five soil samples were pooled to make a single sample of each plot $[16,23]$.

In total, we collected 20 soil samples, i.e. 10 samples from invaded and another 10 from uninvaded plots. Each sample was stored in a zip-lock plastic bag and transported to the Ministry of Agriculture Training Institute $\left(33^{\circ} 22^{\prime} \mathrm{E}\right.$ and $8^{\circ} 55^{\prime} \mathrm{S}$, $1798 \mathrm{~m}$ a.s.l) soil laboratory in Mbeya, Tanzania, for analyses. Soil was sieved through a $2 \mathrm{~mm}$ fine-mesh screen to remove fine rocks and roots, and other unwanted particles. The soil samples were then analyzed for chemical parameters such as total nitrogen $(\mathrm{N})$, phosphorus $(\mathrm{P})$, organic carbon $(\mathrm{OC}), \mathrm{pH}$, electrical conductivity (EC), organic matter (OM), calcium $(\mathrm{Ca})$, magnesium $(\mathrm{Mg})$, potassium $(\mathrm{K})$, manganese $(\mathrm{Mn})$, and cation exchange capacity (CEC).

Recommended standard soil analytical procedures were used $[16,23,24]$. Total OC was determined by the Tinsley method; the $\mathrm{pH}$ was measured potentiometrically in a soil-distilled water suspension (ratio 1:2.5); EC with a saturated soil paste; OM and total $\mathrm{N}$ were determined by the Walkley-black and Kjeldahl methods respectively. Furthermore, $0.5 \mathrm{M} \mathrm{NaHCO}_{3}$ was used to extract the available $\mathrm{P}$ and analyzed colourimetrically with the ascorbic acid molybdate method according to Bray and Curtz No 1; $\mathrm{NH}_{4} \mathrm{C}_{2} \mathrm{H}_{3} \mathrm{O}_{2}$ extracted soil cations $\left(\mathrm{Ca}^{2+}, \mathrm{Mg}^{2+}\right.$ and $\left.\mathrm{K}^{+}\right)$and analyzed on atomic absorption spectrophotometer with flame atomizer (Perkin- Elmer Analyst 100). The Mn was extracted using diethylene triamine pentaacetic acid (DTPA), and CEC was determined with Ammonium Acetate method at pH 7.0.

\subsection{Statistical Methods}

These soil chemical parameters were then compared statistically between invaded and non-invaded plots using a t-test following normality and homogeneity of variance tests using Shapiro-Wilk's and Levene's test, respectively. The statistical software used was Origin version 9.0 SR1 (Origin Pro, 2013) at a significance level of $\alpha=0.05$.

\section{Results}

Parthenium hysterophorus invasion was only observed outside ANP but in villages close by, particularly along the south-eastern boundaries during our field survey (Figure 4). These villages included Ngongongare, King'ori, Oligilai, 
Maleu, Ngurudoto, and Sakila. Parthenium hysterophorus was observed growing in grazing areas, maize and banana fields and along the roadsides. The invasive dominated the road verges and road drainage lines, mainly along the Momela road. A higher density of $P$. hysterophorus was recorded at lower altitude, along roadsides, and in maize fields (Figure 5). It was also observed growing in other disturbed habitats such as landfills or dumping grounds.

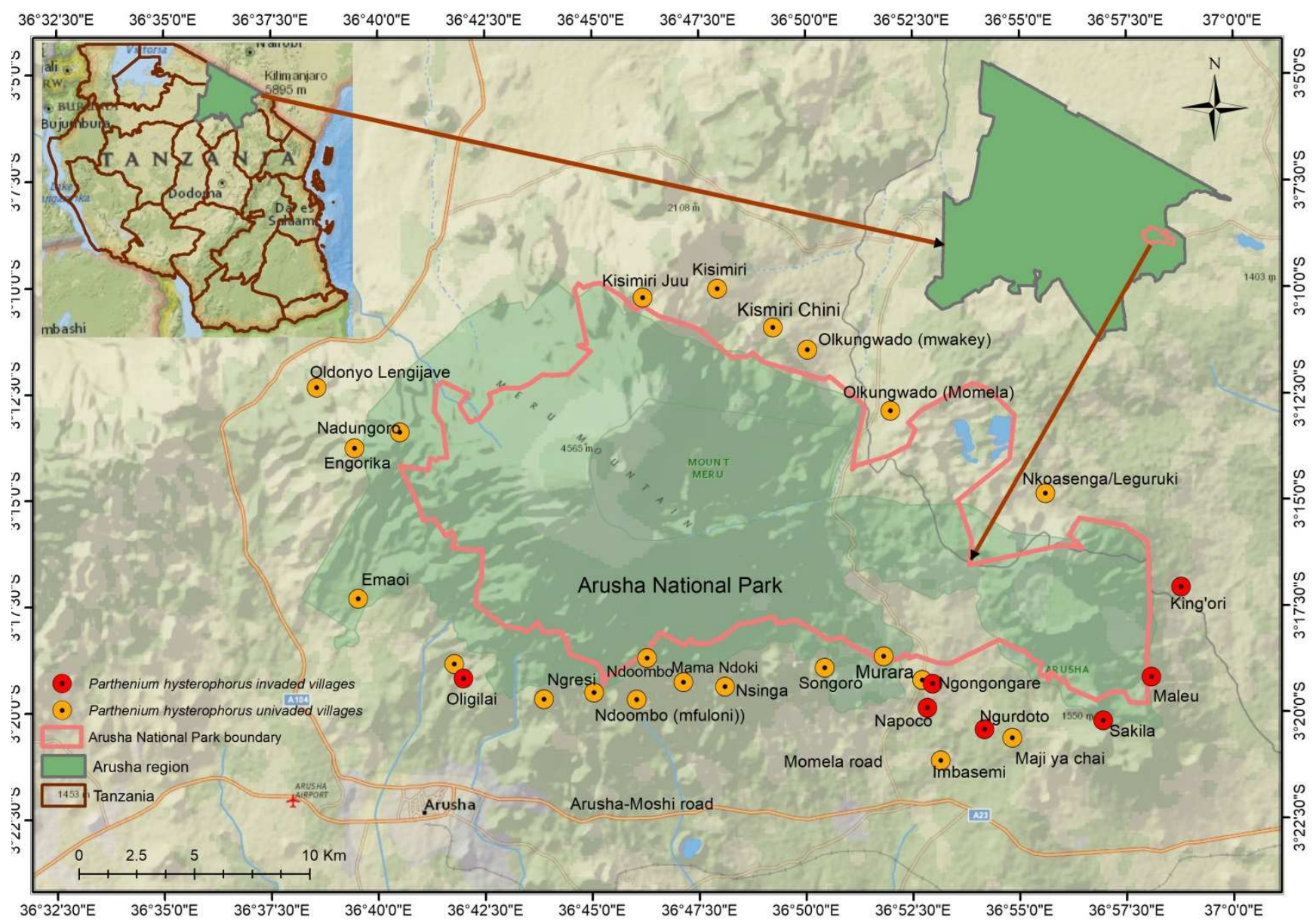

Figure 4. Current spread of P. hysterophorus outside the Arusha national park based on the field survey.

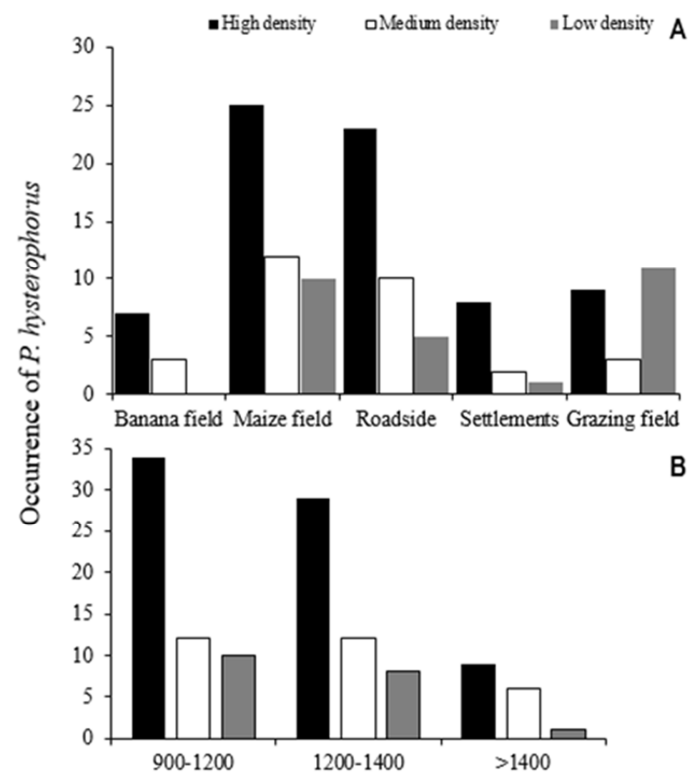

Figure 5. Frequency of P. hysterophorus occurrence in different land use types $(A)$ and elevation in m.a.s.l (B).
Our results show that most soil chemical properties did not differ significantly between sites invaded by P. hysterophorus and control sites (Table 1). However, a slightly significant difference was observed between the invaded and uninvaded plots for EC $(\mathrm{p}=0.046), \mathrm{pH}(\mathrm{p}=0.013)$, and $\mathrm{Ca}(\mathrm{p}=0.043)$ (Table 1). The soil $\mathrm{P}$ concentration was by about $10 \%$ higher in uninvaded than in invaded plots $(\mathrm{p}=0.003$, Table 1) while soil CEC showed the opposite trend, being about $15 \%$ higher in the invaded than in uninvaded plots $(p=0.015$, Table 1$)$.

\section{Discussion}

Our study reveals that $P$. hysterophorus is spreading in some villages closest to the border zones of ANP. However, inside the park is not invaded yet. The spread of $P$. hysterophorus in the villages is possibly aided by the number of factors such as vehicles, fodder collection, grazing, and other socioeconomic activities which disperse the invasive seeds [7, 25].

These factors were reported to have significant relationships with biological invasions in European and some African countries [26, 27]. Vehicles or motorcycles going to 
pick harvests from farms or collect remains for livestock may carry $P$. hysterophorus seeds and spread them to other areas i.e. farms, grazing lands, or rangelands. This was also described by Gervilla et al. [26] and Wilson et al. [28] that contaminant seeds in seed lots constitute a pathway for introducing a plant species into new habitats.

As people walk in $P$. hysterophorus invaded areas, the seeds can drop in their shoes or carried on sole to other locations as contaminants. This could be the reason of why maize fields in our study had the greater number of $P$. hysterophorus invasions in total following roadsides. The current $P$. hysterophorus invasions in these villages is an indicator that the weed threatens to invade the ANP. Thus, if it is left uncontrolled, P. hysterophorus can migrate into the ANP and affects its ecological integrity, ecosystem services and function.

Table 1. A t-test statics of the soil parameters in areas with (invaded) and without (uninvaded) invasion of P. hysterophorus

\begin{tabular}{|c|c|c|c|c|c|}
\hline & \multicolumn{5}{|l|}{ Mean \pm SE } \\
\hline & Uninvaded & Invaded & $\mathbf{T}$ & df & p-value \\
\hline $\mathrm{pH}$ & $6.54 \pm 0.06$ & $6.36 \pm 0.03$ & 2.74 & 18 & 0.013 \\
\hline $\mathrm{E}(\mathrm{CmS} / \mathrm{cm})$ & $0.58 \pm 0.08$ & $0.44 \pm 0.03$ & 2.14 & 18 & 0.046 \\
\hline OC (\%) & $1.79 \pm 0.15$ & $1.43 \pm 0.22$ & 1.59 & 18 & 0.129 \\
\hline Organic matter $(\%)$ & $3.09 \pm 0.25$ & $2.47 \pm 0.38$ & 1.60 & 18 & 0.128 \\
\hline Total N (\%) & $0.11 \pm 0.01$ & $0.12 \pm 0.02$ & -0.65 & 18 & 0.526 \\
\hline $\mathrm{Ca}(\mathrm{Cmol} / \mathrm{kg})$ & $19.37 \pm 0.35$ & $18.11 \pm 0.46$ & 2.18 & 18 & 0.043 \\
\hline $\mathrm{Mg}(\mathrm{Cmol} / \mathrm{kg})$ & $2.22 \pm 0.01$ & $2.21 \pm 0.11$ & 0.44 & 18 & 0.668 \\
\hline $\mathrm{K}(\mathrm{Cmol} / \mathrm{kg})$ & $3.68 \pm 0.26$ & $2.79 \pm 0.37$ & 1.98 & 18 & 0.063 \\
\hline Mn (ppm) & $49.8 \pm 7.01$ & $64 \pm 3.23$ & -1.65 & 18 & 0.116 \\
\hline $\mathrm{CEC}(\mathrm{Cmol} / \mathrm{kg})$ & $34.4 \pm 1.64$ & $43.2 \pm 1.83$ & -2.69 & 18 & 0.015 \\
\hline
\end{tabular}

Bold $p$-values are significant at $p<0.05$

The invaded Momela road which is used by vehicles going to and from Ngarenanyuki through the ANP is the major route through which $P$. hysterophorus seed can be transported into the park. This road is connected to the Arusha-Moshi road which is highly invaded by $P$. hysterophorus. We suggest that the Arusha-Moshi road to be the main source and starting point for $P$. hysterophorus invasions along the Momela road. Previous studies have reported how roadsides act as preferential migration corridor and starting point for $P$. hysterophorus invasion and other invasive species [18, 20, 22]. In this view, the invaded Momela road increases the chance of spreading $P$. hysterophorus into the park. Vehicles from invaded Arusha and Arumeru areas or those using the Momela road may carry $P$. hysterophorus seeds in mud adhered to the tyres into the ANP. The wind produced by these vehicles can also disperse the seeds further from its location to other areas [19, 21, 29].

Additionally, $P$. hysterophorus seeds can enter into the park as a contaminant of tourists, travelers, or workers' possessions $[26,27]$. They may even transport the seeds in mud adhered to their shoes [26]. A study by Vilà and Pujadas [27] claimed that alien plant species introduced in protected areas correlate with the number of visitors. Accordingly, protection of natural habitats or rangelands may not guarantee alien invasive exclusion. So, in order to control alien invasions in natural areas, park ecologists should educate visitors not to releases any seed in protected area; and ensure that neither their belongings nor shoes have seeds contaminants.

Anthropogenic activities associated with change in vegetation structure and composition, as well as fire frequency create a window of opportunity for $P$. hysterophorus invasions in adjacent habitats [27]. Preceding studies unveil that manmade and disturbed areas i.e. agroecosystems, ruderal areas, and roadsides are invaded more compared to pristine areas [6]. Land-use changes, agriculture and livestock in the villages bordering the park are vital means by which $P$. hysterophorus may spread to the ANP's border zones. In our study we found high density of $P$. hysterophorus invasions in maize farms and along road verges. Maize fields are usually left bare without crop or vegetation cover after harvest, and thus, creating a room for $P$. hysterophorus to germinate, colonize and increase in biomass. On the other hand, road verges in our field sites seem to provide suitable conditions for P. hysterophorus to flourish. Studies have shown that road verges can increase soil disturbance, soil moisture, sun exposure and nutrient runoff $[18,19,29]$ conditions needed for many invasives to establish. But, sites distant from the roads can be resistant to alien invasives due to dissimilar abiotic conditions i.e. reduced resource accessibility and disturbance frequency [29]. Human activities nearby the borders of ANP should be controlled and monitored often to preclude $P$. hysterophorus invasion into the park. Road networks in the park must also be monitored because they promote immigration of $P$. hysterophorus and the dispersal of already existing invasives.

Our results have showed that $P$. hysterophorus is invading areas typically at lower altitudes. The ANP which is located at higher altitude could be the main reason of not being invaded by $P$. hysterophorus. At higher altitudes it is difficult for $P$. hysterophorus seeds to be transported by surface runoff into the park [29]. Our findings conform to that of Etana et al. [24] which showed high $P$. hysterophorus invasions at lower altitudes in Awash national park in Ethiopia. Though high elevation seems to impede $P$. hysterophorus from invading the ANP, when its seeds are released into the park can germinate and establish. This is because $P$. hysterophorus grows virtually on all types of habitats and soil with different $\mathrm{pH}$ values [30]. 
In addition, the ANP and its surrounding outer areas have suitable habitats for P. hysterophorus invasions as predicted by Kija et al. [17]. Alien invasives are claimed to modify soil chemical properties of the invaded habitats [16, 23, 30, 31]. But, few studies have studied the impact of $P$. hysterophorus on soil chemical properties [23,31].

Our study showed that $P$. hysterophorus may have a limited negative impact to some soil chemical parameters. This is because most of our soil parameters did not differ significantly between the invaded and uninvaded plots. Our findings conform in some way with that of Etana et al. [24] who found insignificant impact of $P$. hysterophorus on soil OM, total $\mathrm{N}$, $\mathrm{Mg}, \mathrm{K}$, and $\mathrm{Mn}$ invaded plots. In contrary, Timsina et al. [31] found that soil $\mathrm{N}, \mathrm{OM}, \mathrm{K}, \mathrm{P}$ and $\mathrm{pH}$ were highest in the $P$. hysterophorus invaded plots. Furthermore, we found that among the major soil nutrients (N, P and $\mathrm{K}$ ) only $\mathrm{P}$, and other parameters $(\mathrm{pH}, \mathrm{EC}$, and $\mathrm{Ca})$ in our study were lower in the invaded plots. Minor difference in soil OM and $\mathrm{N}$ content between the invaded and uninvaded plots perhaps is due to lower decomposition rate and amount of above-ground biomass [31] of P. hysterophorus in the study sites. Cation exchange capacity was the highest in the invaded plots implying good soil quality and productivity. However, it is not necessary that a soil with a highest CEC is always more fertile as it may sometimes contain acid cations i.e. aluminium $\left(\mathrm{Al}^{3+}\right)$ and hydrogen $\left(\mathrm{H}^{+}\right)$.

Therefore, we suggest that negative impact of $P$. hysterophorus on soil chemical parameters may depend on invasion longevity, intensity, amount of above-ground biomass, and/ or soil type on the invaded habitats. Whether $P$. hysterophorus increases or decreases concentration or content of soil chemical parameters, its invasion is likely to have an overall harmful effect on the functioning of the entire ecosystem or rangeland [31]. Moreover, our results from both survey and soil chemical analysis reiterate the immediate need to control $P$. hysterophorus invasions in protected areas and development of strategies and policy guidelines for managing the invasive.

\section{Conclusion and Recommendation}

Feasible management of biological invasions require information about the distribution and location of alien invasive beforehand. This information is significant because it enables to plan effective management of alien invasive in protected areas, rangelands and agroecosystems. Although the park is uninvaded now, the invasions in the villages indicate that the ANP's biome is under risk. Our study has provided very important information for the distribution of $P$. hysterophorus. We have shown that currently P. hysterophorus is at initial invasion or spread stage towards the borders of ANP. This is the most effective stage for ecologists or invasion biologists to target for managing $P$. hysterophorus. We advise that in order to prevent the immigration of $P$. hysterophorus into the park emphasis must be placed on the control of land-use and socio-economic determinants at the border zones. Policies that integrate local communities in invasive species eradication process should be put in place. We also recommend that $P$. hysterophorus survey within ANP and other protected areas in Tanzania should be conducted, and prevention measure must be prepared beforehand. Besides, appropriate management methods for $P$. hysterophorus are essential to avoid potential negative impact to native biota and economic losses in the country.

\section{Acknowledgements}

We are grateful for the funding provided by the World Bank through its African Centre of Excellence, "Centre for Research, Agricultural advancement, Teaching Excellence and Sustainability in Food and Nutritional Security (CREATES)", in the School of Life Sciences and Bioengineering at the Nelson Mandela Institution of Science and Technology (NM - AIST) in Arusha, Tanzania; the grant number CREDIT No. 5799-TZ. We are also greatly indebted to the Idea Wild for supporting us with research equipment. We thank Tanzania National Park Authority and Tanzania Wildlife Research Institute for giving us a research permit. We appreciate the help of our field assistants.

\section{References}

[1] L. Gao, B. Hou, M. L. Cai, J. J. Zhai, W. H. Li, and C. L. Peng (2018). General laws of biological invasion based on the sampling of invasive plants in China and the United States. Global Ecology and Conservation, 1-14.

[2] N. Gassó, W. Thuiller, J. Pino, and M. Vilà (2012). Potential distribution range of invasive plant species in Spain. NeoBiota, 12: $25-40$.

[3] J. Ilukor, S. Rettberg, A. Treydte, and R. Birner (2016). To eradicate or not to eradicate? Recommendations on Prosopis juliflora management in Afar, Ethiopia, from an interdisciplinary perspective. Pastoralism, 6 (1): 1-14.

[4] M. Kaur, N. K. Aggarwal, V. Kumar, and R. Dhiman, (2014). Effects and management of Parthenium hysterophorus: A weed of global significance. International Scholarly Research Notices, 1-12.

[5] F. Ojija, S. E. J. Arnold, and A. C. Treydte (2019). Impacts of alien invasive Parthenium hysterophorus on flower visitation by insects to co-flowering plants. Arthropod-Plant Interactions, 13 (5): 719-734.

[6] J. C. Lake and M. R. Leishman (2004). Invasion success of exotic plants in natural ecosystems: the role of disturbance, plant attributes and freedom from herbivores. Biological Conservation, 117 (2): 215-226.

[7] CABI, "Invasive species compendium: Parthenium hysterophorus (parthenium weed). https://www.cabi.org/isc/datasheet/45573. Accessed on 30-10-2019.

[8] E. Gerber, C. Krebs, C. Murrell, M. Moretti, R. Rocklin, and U. Schaffner (2008). Exotic invasive knotweeds (Fallopia spp.) negatively affect native plant and invertebrate assemblages in European riparian habitats," Biological Conservation, 141 (3): 646-654. 
[9] Y. Sun and A. Junod (2017). Invasive plants differ from native plants in their impact on native communities. Journal of Vegetation Science, 28 (6): 1250-1259.

[10] R. M. Niemiec, N. M. Ardoin, C. B. Wharton, and G. P. Asner (2016). Motivating residents to combat invasive species on private lands: social norms and community reciprocity. Ecology and Society, 21 (2): 30.

[11] A. M. Reid, L. Morin, P. O. Downey, K. French, and J. G. Virtue (2009). Does invasive plant management aid the restoration of natural ecosystems? Biological Conservation, 142 (10): 2342-2349.

[12] J. I. Watling, C. R. Hickman, and J. L. Orrock (2011). Invasive shrub alters native forest amphibian communities. Biological Conservation, 144 (11): 2597-2601.

[13] I. Stiers, N. Crohain, G. Josens, and L. Triest (2011). Impact of three aquatic invasive species on native plants and macroinvertebrates in temperate ponds. Biological Invasions, 13 (12) 2715-2726.

[14] A. A. Bajwa, M. Farooq, A. Nawaz, L. Yadav, B. S. Chauhan, and S. Adkins (2019). Impact of invasive plant species on the livelihoods of farming households: evidence from Parthenium hysterophorus invasion in rural Punjab, Pakistan. Biological Invasions, 21 (11): 3285-3304.

[15] F. Ojija, S. E. J. Arnold, and A. C. Treydte (2019). Bio-herbicide potential of naturalised Desmodium uncinatum crude leaf extract against the invasive plant species Parthenium hysterophorus. Biological Invasion, 21 (12): 3641-3653.

[16] O. O. Osunkoya, O. A. Akinsanmi, L. S. A. Lim, C. Perrett, J. Callander, and K. Dhileepan (2017). Parthenium hysterophorus L. (Asteraceae) invasion had limited impact on major soil nutrients and enzyme activity: Is the null effect real or reflects data insensitivity? Plant and Soil, 420 (1-2): 177194.

[17] B. Kija, C. Mweya, M. Mwita, R. Fumagwa, and H. Kija (2013). Prediction of suitable habitat for potential invasive plant species Parthenium hysterophorus in Tanzania: a short communication. International Journal of Ecosystem, 3 (4): 82 89.

[18] Y. Kosaka, B. Saikia, T. Mingki, H. Tag, T. Riba, and K. Ando (2010). Roadside distribution patterns of invasive alien plants along an altitudinal gradient in Arunachal Himalaya, India. Mountain Research and Development, 30 (3): 252-258.

[19] S. L. Flory and K. Clay (2009). Invasive plant removal method determines native plant community responses. Journal of Applied Ecology, 46 (2): 434-442.
[20] S. Thapa, V. Chitale, S. J. Rijal, N. Bisht, and B. B. Shrestha (2018). Understanding the dynamics in distribution of invasive alien plant species under predicted climate change in Western Himalaya. PLOS ONE, 13 (4): e0195752.

[21] M. Von Der Lippe and I. Kowarik (2007). Long-distance dispersal of plants by vehicles as a driver of plant invasions. Conservation Biology, 21 (4): 986-996.

[22] D. Christen and G. Matlack (2006). The role of roadsides in plant invasions: A demographic approach. Conservation Biology, 20 (2): 385-391.

[23] O. O. Osunkoya and C. Perrett (2011). Lantana camara L. (Verbenaceae) invasion effects on soil physicochemical properties. Biology and Fertility of Soils, 47 (3): 349-355.

[24] A. Etana, E. Kelbessa, and T. Soromessa (2011). Impact of Parthenium hysterophorus L. (Asteraceae) on herbaceous plant biodiversity of Awash National Park (ANP), Ethiopia. Management of Biological Invasions, 2 (1): 69-80.

[25] M. E. Safdar, A. Tanveer, A. Khaliq, and R. Maqbool (2016). Critical competition period of parthenium weed (Parthenium hysterophorus L.) in maize. Crop Protection, 80: 101-107.

[26] C. Gervilla, J. Rita, and J. Cursach (2019). Contaminant seeds in imported crop seed lots: A non - negligible human mediated pathway for introduction of plant species to islands. Weed Research, 59 (3): 245-253.

[27] M. Vilà and J. Pujadas (2001). Land-use and socio-economic correlates of plant invasions in European and North African countries. Biological Conservation, 100 (3): 397-401.

[28] C. E. Wilson, K. L. Castro, G. B. Thurston, and A. Sissons (2016). Pathway risk analysis of weed seeds in imported grain: A Canadian perspective. NeoBiota, 30: 49-74.

[29] A. Lázaro-Lobo and G. N. Ervin (2019). A global examination on the differential impacts of roadsides on native vs. exotic and weedy plant species. Global Ecology and Conservation, 17: $\mathrm{e} 00555$.

[30] R. A. Qureshi, S. A. Gilani, M. A. Ghufran, and K. N. Sultana (2006). Effects of Parthenium hysterophorus L. on Soil characteristics initially inhabited to Cannabis sativa L. Pakistan Journal of Biological Sciences, 9 (15): 2794-2797.

[31] B. Timsina, B. B. Shrestha, M. B. Rokaya, and Z. Münzbergová (2011). Impact of Parthenium hysterophorus L. invasion on plant species composition and soil properties of grassland communities in Nepal. Flora - Morphology, Distribution, Functional Ecology of Plants, 206 (3): 233-240. 